\title{
O VALOR ESTÉTICO: ENTRE UNIVERSALIDADE E EXCLUSÃO
}

\author{
Jaime Ginzburg
}

Entre os debates da crítica literária contemporânea, um dos mais exigentes se refere ao problema dos critérios de valorização de obras literárias. Observamos em muitos aspectos, na literatura brasileira recente, a diversidade da produção, em termos formais e temáticos, e isso tem estimulado uma ampla reflexão sobre a adequação de categorias tradicionais para lidar com essa produçãa. Em meio a essa reflexão, constantemente são formuladas dúvidas sobre a qualidade e a relevância das obras contemporâneas.

Em tempos em que a complexidade da indústria cultural desafia as ciências humanas como um campo cifrado, parece improvável que a relevância de obras literárias possa ser avaliada de modo independente do impacto do mercado. O questionamento do valor estético poderia demandar uma percepção crítica dos mecanismos de descartabilidade de valor propostos pelo consumo.

Esse problema causa preocupação, mas a atenção deste estudo se volta para apenas um aspecto do debate sobre o valor estético. Trata-se de articular a apreciação de obras literárias com a exposição à violência social contemporânea. Especificamente, cabe pensar o que pode ser considerado esteticamente relevante, ou belo, ou passível de contemplação, em um contexto de sujeição constante ao impacto agressivo de uma realidade caracterizada por conflitos sociais e impasses éticos em ampla escala. Dizendo de outro modo, se nos encontramos em um constante estado de suspensão entre insegurança, medo e ansiedade, associado a tensões políticas e econômicas, o que se apresenta como interessante ao olhar?

Em um contexto de real traumático, o padrão esperado não é necessariamente a atração pelo estranhamento e pelo choque, como estratégia de tomada de consciência sobre a potência destrutiva com que nos confrontamos constantemente ao contemplar o mundo à nossa volta. Como evidencia a indústria do entretenimento, muitos procuram a literatura, a música e o cinema em busca de alívio para o sofrimento. Essa busca consiste, em muitos casos, em uma necessidade de construção de ilusōes perceptivas. Negaçōes ou fugas, movimentos que propiciem descanso às retinas fatigadas. 
Se essa hipótese tem algum sentido, é possível discutir o problema dos critérios de avaliação de obras literárias à luz da necessidade de crítica desses movimentos. O fato de estarmos expostos a um processo social e político intensamente violento, em que a indústria cultural potencia em escala indescritível as imagens da violência para além de qualquer capacidade de assimilação, motivaria a adesão a produçôes culturais capazes de propiciar pontos de conforto.

Quando o debate se mantém no campo do senso comum, afirmar o interesse por uma obra não exige necessariamente justificativas. Reações emocionais podem ser suficientes. Diante da proposição do problema "por que é boa uma obra literária?", respostas como "é bonita", "é profunda" ou "me identifico com ela", em situaçôes informais, podem ser completamente suficientes. O imediatismo contribui para a suficiência da reação trivial, pois para os interesses do consumo, a superficialidade é funcional. Mecanismos publicitários, operações de marketing e listas de best-sellers, entre outros procedimentos de manipulação, podem ajudar a constituir fundamentos de legitimação de gosto.

Reações triviais não descartam o aspecto distintivo de uma atribuição de valor. As frases "é bonita" e "é profunda" podem servir como marcadores de superioridade, se o interlocutor assume haver implicitamente um julgamento de repertório - como em "ébonita, enquanto outras que conheço são feias”. Entre consumidores, no campo das operações de mercado, aspectos distintivos podem agir como segmentação do consumo, orientando faixas de público, e também como indicadores do grau de facilidade com que uma produção será descartada em favor de outras. Um dos principais instrumentos de sustentação de empresas da indústria cultural, em suas ações de persuasão, consiste em fazer um consumidor acreditar (mesmo havendo um visível esquema massivo de distribuição e vendas) que ele está livre para atribuir valor distintivo a cada produto.

Quando o debate ocorre no campo acadêmico, podemos esperar algo diferente. Cabe então uma argumentação que sustente a definição de critérios de qualidade. $\mathrm{O}$ mesmo problema, "por que é boa uma obra literária?”, pode assumir assim estatuto científico ou filosófico. São necessários, nesse caso, conceitos capazes de sustentar uma argumentação em favor de um critério de gosto.

Cabe estabelecer então se, em termos acadêmicos, os critérios de avaliação devem coincidir com o senso comum, e se devem favorecer o conforto perante uma realidade traumática. Em outras 
(SCHELLING, Friedrich. La relación de las artes figurativas con la naturaleza. Buenos Aires: Aguilar, 1959: 49.) palavras, a crítica contemporânea deve atribuir valor a obras argumentando em favor de percepçóes que nos iludam com a imagem de um mundo conciliado?

O contexto brasileiro das últimas duas décadas conheceu tanto a consolidação da auto-ajuda como um setor editorial de investimento seguro quanto a acentuação do interesse do público por obras que não receberam reconhecimento nas listas universitárias de leituras para vestibulares, como O alquimista, Harry Potter e biografias de figuras midiáticas. Numerosos fatores podem ajudar a compreender esse processo merecedor de prioritária atenção. Em hipótese, um desses fatores, em termos de psicologia social, pode ser a busca de elementos afirmativos, em suma, de um otimismo dotado de solidez moral, capaz de apontar para a superação individual de dificuldades sociais, econômicas e políticas.

No idealismo alemão, Friedrich Schelling, como teórico de estética, realizou uma defesa otimista de desígnios morais e religiosos. Obras literárias, para o filósofo, deveriam propor um mundo melhor do que ele de fato é, para elevar os seres humanos em seus valores e interesses. Schelling propõe que a arte deve preservar o homem "do vazio, da debilidade, da nulidade interior, esperando que tente alcançar a beleza por uma sábia harmonia”. "Há uma atualidade evidente em um dos aspectos defendidos por Schelling: é compreensível a escolha por uma vitória do bem moral. Consumidores em busca de entretenimento podem optar por escolhas que removam o sentimento de "debilidade, de nulidade interior", em favor de uma atitude otimista perante a realidade.

Não se trata apenas de observar que a auto-ajuda e Paulo Coelho propõem investimentos narcísicos para compensar dificuldades de integração social, nem apenas de perceber que a venda de livros otimistas é favorecida pelo aumento do impacto agressivo da realidade cotidiana. Mais do que isso, trata-se de perguntar em que medida esses processos de consolidação de relações entre autores, editoras e público supõem concepçôes estéticas que não são suficientemente compreendidas pelos pesquisadores universitários. Se as teorias estéticas são construídas em direta relação com valores distintivos, é inteiramente previsível que muitos intelectuais prefiram discutir conceitos que consigam descrever as obras que apreciam e justificar suas escolhas de leitura. Com isso, é plausível que esses conceitos sejam inadequados para explicar e legitimar obras que rejeitam, ou que sejam feitos esforços para que os conceitos justifiquem com propriedade suas rejeições. 
No entanto, é ingênuo imaginar que os juízos de valor, como operadores distintivos, não estejam sujeitos ao debate e à controvérsia. Em muitos casos, para se distanciarem de conflitos - não é fácil debater posiçôes sobre literatura de fato, mantendo clareza e respeito -, intelectuais optam por concepções estéticas que parecem assegurar a inutilidade da discussão. Uma obra é boa então porque foi possível ao intelectual, genial ou erudito, reconhecer isso. Opiniōes diferentes são desautorizadas ou despreparadas. Não é apenas o valor que é distintivo nesse caso, mas sobretudo o lugar de que fala o intelectual.

Para assegurar que apenas poucos eleitos sejam reconhecidos como capazes de atribuir valor de modo legítimo, e que não reste alternativa aos leitores leigos a não ser segui-los em obediência, há várias estratégias conhecidas. Uma delas é comum e constante: afirmar que o valor de uma obra é inteiramente inerente a ela. "Valor" então seria uma substância, não uma atribuição; um dado a priori, não uma construção histórica. Bons leitores o reconhecem, leitores fracos nada vêem. Essa perspectiva comum não é apenas arrogante intelectualmente, ela é francamente autoritária. $\mathrm{O}$ valor considerado inerente à obra consiste em capital intelectual, ${ }^{*}$ indicador de relevância e prestígio de quem o reconhece.

Um ponto de vista que pode ser lembrado, neste caso, é o de Afrânio Coutinho, responsável por diversos livros de ampla influência nos estudos literários brasileiros ao longo do século XX. Coutinho escreve que o valor de uma obra reside "no seu aspecto estético-literário, que lhe é comunicado pelos elementos específicos, componentes de sua estrutura, e pela finalidade precisa de despertar no leitor o tipo especial de prazer, que é o sentimento estético". Segundo ele,

Através das obras literárias, tomamos contato com a vida, nas suas verdades eternas, comuns a todos os homens e lugares, porque são as verdades da mesma condição humana. Ela tem existência própria, é ela e nada mais, e seu campo de ação e seus meios são as palavras e os ritmos usados por si mesmos e não como veículos de valores extraliterários.

Estamos diante de uma posição que defende uma autonomia do campo estético com relação ao contexto histórico-social, posição que o autor defendeu em muitos de seus trabalhos. Além disso, temos uma conexão direta entre o "sentimento estético" e as "verdades eternas" da "condição humana".
" (BOURDIEU, Pierre. As regras da arte. São Paulo: Companhia das Letras, 1996.)

"(COUTINHO, Afrânio. Notas de teoria literária. Rio de Janeiro: Civilização Brasileira, 1976: 8.)

"(Idem, p. 10) 
Em Coutinho temos a explicitação de um fundamento universalista nas condições de avaliação das obras. Ele é claro em defender a idéia, amplamente difundida no new criticism americano e fortemente influente na crítica brasileira ao longo do século XX, de uma condição humana universal.

Esse fundamento permitiria dispensar variáveis temporais e espaciais, que especificariam as condições de existência. Falar em idealismo e em metafísica para descrever essa concepção não é suficiente. É preciso notar seu caráter purista e seu investimento no efeito emocional das obras. Trata-se de uma posição que, mascarada de distanciamento da política, é em si mesma fortemente marcada por uma ideologia conservadora. Se as verdades humanas são eternas, invariáveis, pouco importam os conflitos históricos circunstanciais, as contingências tensas. Evidentemente não é assim que pensam o feminismo e o movimento negro. A defesa de verdades eternas pode coincidir, convenientemente, com o reforço do recalque da violência histórica. A posição de Afrânio Coutinho, afinal, não corresponde ao interesse de toda a humanidade. Ela serve para reforçar as condições de desigualdade e exclusão e silenciar as vozes de segmentos sociais que historicamente não tiveram direito à manifestação no campo das letras.

Não são pequenos os esforços de intelectuais para manter a literatura distante do mundo sangrento da realidade traumática. Programas de pós-graduação brasileiros, no momento presente, continuam produzindo teses e dissertações que usam expressões próximas a "condição humana" e "sentimento estético" em acepções similares às de Afrânio Coutinho. Muitas vezes os autores dos trabalhos não estão suficientemente conscientes das escolhas que realizam, e defendem suas posições sem atentar à sua inserção na história das idéias e dos estudos literários no país. Trabalhos descritivos e classificatórios freqüentemente rejeitam a atribuição de historicidade a obras, e muitas vezes renunciam a explicitar critérios para as delimitações e avaliações de seus objetos. E não deixa de ocorrer que, na mais ingênua boa-fé, uma pesquisa defenda a grandeza de um autor pela sua universalidade, precisamente no sentido de que sua obra transcenderia ao mundo sujo da sociedade em conflito. Com certeza, seria um alívio, como sublimação da insistente incapacidade da humanidade em estabelecer paz, que todos os seres humanos se reconhecessem como essencialmente idênticos. Não haveria razão para conflitos. Seria a eliminação de todas as fantasmagorias anunciadas em Marx, Freud, Adorno e Levinas. 
No entanto se trata de puro delírio: construção de uma imagem da realidade sem diferenças. Esse universalismo falseia o fato traumático de que estamos expostos ao conflito intensamente, em um processo histórico-social antagônico, que não admite síntese conciliatória, conforme a meticulosa avaliação da Dialética negativa de Adorno. Esse universalismo, incompatível com uma negatividade crítica, escolhe ficar cego diante das tensóes históricas que motivam escritores e impregnam obras.

A noção de universalidade de valor, em si mesma, mereceria longa e dedicada reflexão, atenta às vertiginosas implicações do emprego da palavra "universal", seus componentes morfológicos, sua polissemia e suas apropriações antropológicas e históricas. É uma palavra que pode ser muito cativante em contextos de elevada tensão política. $\mathrm{O}$ emprego dessa palavra pede explicitação de ponto de vista de sua enunciação: a que universo nos referimos, a cada vez que dizemos essa palavra? Estaria o responsável pela enunciação projetando o universo a partir de si mesmo, modelando seus limites a partir de seus interesses específicos?

Nesses termos, podemos retomar a questão básica - "por que é boa uma obra literária?" A historiografia conservadora, investindo na idéia de universalidade, poderá falar em termos como: profundidade; densidade; reflexividade. A contribuição de uma obra para a civilização depende, nesse sentido, da profundidade com que penetra no interior da condição humana e revela seus fundamentos essenciais.

Esse vocabulário, adotado em diversas perspectivas teóricocríticas, serve em situações em que a argumentação se desencontra de si mesma. Podemos afirmar que uma obra é profunda, ou que ela provoca reflexão, como um modo de elogiar ou registrar seu poder de impacto, mas ao mesmo tempo não estamos indicando nada específico. É possível sugerir que um estudo de lógica formal seria capaz de medir exigências reflexivas de um texto, como fazem abordagens empíricas, mas isso não permitiria mensurar valor, como se fosse uma substância em seu interior - o valor é uma atribuição historicamente construída. Frases como "esta obra tem densidade" não são objetivas, e evocam primariamente os interesses dos sujeitos que as enunciam.

Com uma tradição literária no horizonte, podemos acreditar em critérios de valor estabelecidos com solidez: autoridades acadêmicas, dotadas de estofo intelectual e rigor comparativo, são con-
" (ADORNO, Theodor. Negative dialectics. Nova York: The Continuum Publishing Company, 1999: 317-318.) 
•(BLOOM, Harold. O cânone ocidental. Rio de Janeiro: Objetiva, 1995.)

- (BLOOM, Harold. Gênio Rio de Janeiro: Objetiva, 2003.)

•(BLOOM, Harold. O cânone ocidental. Rio de Janeiro: Objetiva, 1995: 24-25.)

·PERRONE-MOISÉS, Leyla. Altas literaturas. São Paulo: Companhia das Letras, 1998.)

(COUTINHO, Eduardo. "Literatura comparada, literaturas nacionais e o questionamento do cânone", Revista brasileira de literatura comparada $\mathrm{n}^{\circ} 3$, Rio de Janeiro: Abralic, 1996: 72.) sideradas responsáveis pela segurança das avaliações duradouras. Historiadores da literatura, ao elaborarem repertórios de autores e obras caracterizados como de alto valor, teriam constituído parâmetros a serem utilizados no trabalho que nos cabe no presente. Em perspectiva canônica, esse trabalho consistiria em reproduzir valores, confirmar avaliações, e interpretar a produção do presente à luz da continuidade do conhecimento estabelecido.

O problema muda de figura se deixamos de lado a defesa da perspectiva canônica. A desconfiança com relação a avaliações consideradas seguras pode trazer dificuldades. Não se trata apenas de colocar dúvidas sobre opiniões freqüentemente consideradas inequívocas, mas, mais do que isso, de discutir as condições em que essas opiniōes circulam. Tomemos, por exemplo, de um lado, Harold Bloom, com $O$ cânone ocidental * e Gênio, caracterizando a superioridade de um conjunto de autores de sua eleição com relação a outros como um dado demonstrável e seguro. De outro, aqueles que ele caracteriza como seus inimigos acadêmicos - críticos interessados em questóes como gênero, etnia, raça, religião e orientação sexual.

O debate, tal como examinado por Bloom, é de fundo político e institucional. Envolve o futuro dos departamentos de inglês, e a definição de prioridades para os estudos literários.

(...) a crítica literária, como uma arte, sempre foi e sempre será um fenômeno elitista. Foi um erro acreditar que a crítica literária podia tornar-se base para a educação democrática ou para melhorias da sociedade. (...) O que mais me interessa é a fuga ao estético entre tantos de minha profissão (...)

No Brasil, ressonâncias desse confronto estão em trabalhos de Leyla Perrone-Moisés. * Faz parte das discussões recentes em congressos de estudos literários o enfrentamento do problema dos limites e das especificidades da área, e a historiografia canônica é um dos objetos centrais de avaliação por parte dos interessados nessa discussão.

Roberto Reis, Bobby Chamberlain e Eduardo Coutinho participaram da discussão dos procedimentos da historiografia canônica. Coutinho examinou o que há de excludente da tradição canônica no Brasil, selecionando alguns segmentos sociais em desfavor de outros. * A situação do cordel, da tradição oral e dos registros indígenas chama a atenção em termos de lacuna histórica.

De acordo com Roberto Reis, cabe discutir por que em nosso cânone "há poucas mulheres, quase nenhum não-branco e muito 
provavelmente escassos membros dos segmentos menos favorecidos da pirâmide social". Ele observa uma relação direta entre os modelos canônicos e a desigualdade social do país. Chamberlain também acredita em uma conexão entre os parâmetros de exclusão estética e as experiências de exclusão social.*

Levando em conta as afirmaçóes de Harold Bloom, podemos sinalizar tendências dentro do debate. A posição canônica é alheia a interesses democráticos, e considera haver, nas discussões recentes voltadas para o resgate de segmentos sociais, uma "fuga ao estético". Posições como as de Reis, Chamberlain e Coutinho vêem nos estudos literários componentes de exclusão social, e apontam para lacunas históricas. Trata-se ostensivamente de uma arena política, sem deixar de ser um debate no campo estético.

Um dos problemas em pauta consiste em uma conexão entre conflitos no campo social e econômico, que dizem respeito à tradição patriarcal e à desigualdade promovida pelo capitalismo, e conflitos de opinião, que dizem respeito ao que é considerado relevante artisticamente. Essa conexão aponta para o campo da memória cultural. O que deve ser lembrado, o que pode ser esquecido? O campo da memória cultural é ainda um campo pedagógico. Que autores e obras devem ser priorizados em escolas e universidades? quais podem ser ignorados pelo saber legitimado institucionalmente?

Nesse sentido, discutir critérios de avaliação de obras literárias exige discutir política da memória. Isso é particularmente importante no contexto de sociedades fortemente autoritárias, com linhagens institucionais de orientação ditatorial, caso da brasileira. Levando em conta Nelly Richard, " estaríamos diante de um problema de constituição de memória e esquecimento no campo coletivo. As decisões de instituições, e dos intelectuais que as representam, podem influir de modos diretos e indiretos nas condiçôes de circulação e recepção de obras literárias. Essas condições podem definir sua permanência no mercado, nas bibliotecas e nos horizontes de expectativa dos leitores.

Esse quadro leva a pedir dos defensores das diferentes posições do debate a explicitação de seus pressupostos, mas isso não ocorre sem que se apresentem mais problemas. Na crítica brasileira contemporânea, a questão "por que é boa uma obra literária?” se faz ouvir junto com questôes amplas como "podemos considerar esse texto como literatura?", uma vez que estudos de crônicas, cartas, diários, autobiografias, testemunhos e blogs já estão acontecendo
"(REIS, Roberto. "Cânon". Em: JOBIM, José Luis (org.). Palavras da crítica. Rio de Janeiro: Imago, 1992: 73.)

(CHAMBERLAIN, Bobby. "Of charters, paradigms and spawning fish: a look at Brazilian literary periodization and canon-formation", Brasil/Brazil n ${ }^{\circ} 10$, Porto Alegre: PUC-RS/Mercado Aberto/Brown University, 1993: 17)

"(RICHARD, Nelly. "Políticas da memória e técnicas do esquecimento". Em: MIRANDA, Wander Melo (org.). Narrativas da modernidade. Belo Horizonte: Autêntica, 1999.) 
(Cf. SARLO, Beatriz. Tempo passado. São Paulo: Companhia das Letras, 2007; AGUIAR, Flávio et al. (org.). Gêneros de fronteira. São Paulo: Xamã, 1997; SELIGMANN-SILVA, Márcio. (org.). História, memória, literatura. Campinas: Unicamp, 2003.)

(ADORNO, Theodor. Teoria Estética. Lisboa: Martins Fontes, 1988: 16)

"NATALI, Marcos Piason. "Além da literatura", Literatura e sociedade $n^{\circ}$ 9, São Paulo: DTLLC/USP 2006: 33-36.) dentro do campo dos assim chamados estudos literários, bem como textos ficcionais estão sendo investigados por pesquisadores de diversas disciplinas, com propósitos próprios."

Cabe perguntar se Harold Bloom tinha razão ao afirmar que está havendo uma fuga ao estético entre os pesquisadores de estudos literários, e vale a pena enfocar a mesma pergunta no contexto da crítica brasileira contemporânea. Claro que fazer essa pergunta implica avançar para outra: o que Bloom estaria entendendo por "estético" ao enunciar a frase? Se a fuga ao estético corresponde ao interesse por questôes ligadas à repressão social e à desigualdade, então o estético poderia estar num campo alheio aos conflitos históricos de exclusão. Essa hipótese sugeriria então uma oposição entre o campo estético e a resistência à repressão.

Se assumirmos uma perspectiva adorniana, essa concepção é contestada, e mais do que isso, pode ser flagrada como estratégia ideológica. Para Adorno, "os antagonismos não resolvidos da realidade retornam às obras de arte como os problemas imanentes de sua forma". " Problemas histórico-sociais não apenas se relacionam com o estético: são constitutivos das obras. Porém, evidentemente, Bloom não pensa como Adorno.

Poderíamos então enfrentar mais um problema conceitual: se todo valor é atribuição historicamente construída, poderíamos cair em um relativismo extremo, em que tudo está sujeito a debate. Nenhuma obra seria boa por evidência imediata, estaríamos sem certezas e, em última instância, não teríamos nenhuma segurança sobre o que deve ser lido ou não. Como professores, estaríamos à mercê de nós mesmos na tarefa delicada de decidir o que fazer.

A imagem do relativismo extremo é confortável para defender posiçôes conservadoras, incluindo a defesa submissa e acrítica do cânone. $\mathrm{O}$ momento presente do debate em teoria literária não assegura nenhum consenso. Cabe enfatizar que, no presente, defender posiçōes similares às de Afrânio Coutinho consiste em fechar os olhos para a dor dos outros. Como explica Marcos Piason Natali, falar de literatura utilizando a noção de "universal" e negando "o reconhecimento, cada vez mais difícil de evitar, da diversidade cultural do mundo" significa, em última instância, tratar o processo histórico do Ocidente, incluindo as colonizações, os movimentos de consolidações de territórios, como se ele não tivesse sido "empreendido sob ameaça de morte", " com genocídios e exclusóes.

Se consideramos conservadora e autoritária a posição de defender que uma obra de arte é boa porque manifesta uma univer- 
salidade, que mascara conflitos, podemos também considerar passível de controvérsia a posição segundo a qual uma obra é relevante porque corresponde a valores de um grupo social específico. O preço pago por trabalhos de crítica que se assumem como associados a uma causa, como o feminismo ou o movimento negro, é o confronto com os interesses hegemônicos. Esses interesses propóem, constantemente, seguindo aqui em parte os termos de Harold Bloom, que trazer questões de sexo e raça para a crítica literária é compensar um fracasso social - como a militância política é insuficiente para dar conta das demandas sociais e obter vitória na arena política, o mundo acadêmico sublimaria essa falha na discussão da arte e da cultura. Esse argumento repetido com freqüência reduz os movimentos sociais a caricaturas e sugere, com covardia, que o conservadorismo é vencedor desde e para sempre.

Porém, se é entretenimento que o público leitor quer, em que medida essa politização do gosto tem chances de se firmar? Se os consumidores querem recusar imagens impactantes da realidade traumática, se querem o otimismo afirmativo em desfavor da negatividade crítica, livros associados à tentativa de resgate de vozes silenciadas pela história podem encontrar dificuldades de circulação e recepção. A ilusão de universalidade é mais fácil de construir do que a empatia com a dor do outro.

\section{Jaime Ginzburg}

Professor da Universidade de São Paulo e pesquisador do CNPq.

\section{Resumo}

Este estudo propõe uma reflexão sobre o conceito de valor estético, levando em conta relaçóes entre o conceito de universalidade, exclusão social e violência contemporânea.

\section{Abstract}

This study brings a reflection on aesthetic values, trying to consider connections between universality, social exclusion and contemporary violence.

\section{Resumen}

Esta investigación presenta una reflexión acerca del concepto de valor estetico, procurando considerar relaciones entre la idea de universalidad, la exclusión social y la violencia contemporanea.
Palavras-chave: valor estético; universalidade; exclusão, violência.

Key words: aesthetic value; universality; exclusion, violence.

Palabras Ilave: valor estético; universalidad; exclusión; violencia

Recebido em 30/03/2008

Aprovado em 14/04/2008 